\title{
FAILURE OF STAINLESS STEEL 304L WATER TANK DUE TO INTERGRANULAR CORROSION CAUSED BY WELD DEFECTS AND CHLORIDES
}

\author{
M. A. KOVALEV, A.N. KARANDASHEV \& N.V.ZHUKOV
}

Peter the Great St. Petersburg Polytechnic University

\begin{abstract}
The paper presents the results of capacitive equipment failure analysis. The product was operated at elevated temperatures in an environment containing chlorides. The incident is interesting because it contains most possible defects and violations of technological processes for this type of equipment, which, as a result, led to equipment failure. The work investigated the defects of the welded joint of stainless steel AISI 304L from which the container was made, metallographic studies of the destroyed zones and tests for intergranular corrosion were carried out. It is shown that the main cause of fracture is associated with the formation of intergranular cracks. Based on the results of the work, recommendations were proposed for eliminating subsequent destruction.
\end{abstract}

KEYWORDS: Capacitive Equipment, Boiler, Intergranular Corrosion, Water Heating Equipment, AISI 304L

Received: Jun 09, 2020; Accepted: Jun 29, 2020; Published: Sep 26, 2020; Paper Id.: IJMPERDJUN20201441

\section{INTRODUCTION}

Failure analysis of products and structures is a common problem solved by research laboratories. This is especially true for corrosion laboratories which operating activity usually consist of acceptance tests and analyzes of equipment failure. The destruction of products can be caused by various reasons related to operating conditions, human factors, force majeure factors, etc. [1]. Cases of equipment failure because of corrosion damage are widespread. However, not always an aggressive environment and its change. For example, the service life can be significantly changed [2]. Corrosion tests in the intended operating environment. Many works, especially in the oil and gas industry $[3,4,5,6$,$] .$

Stainless steels have high corrosion resistance, ductility, and structural stability over a wide temperature range, but can be subject to various types of corrosion damage. Numerous cases of equipment failure due to fracture associated with cracking (sulfide stress corrosion cracking, chloride-induced cracking, intergranular corrosion) are known. Damage mechanisms depend on the operating conditions. The main reason is associated with local corrosion damage to stainless steels because of violations of the passive film by chloride ion in the most structurally sensitive zones - welding, bending, metal defects. Corrosion damage of stainless steels in chloride-containing environments often leads to the destruction of heat exchange equipment, water heating in various industries $[7,8,9]$.

The article deals with the case of capacitive equipment destruction during operating in corrosive environment. The product was used to heat a solution containing chlorides. The main defect found on the equipment body was through cracks. As a rule, in the case of incidents related to corrosion, destruction is the result of deficiencies in design documentation or delivery control of finished products [10,11]. Also, the use of metal products that do not meet the requirements of certificates or do not possess the properties specified in the design documentation is a common cause of equipment failure. Based on previous work, this problem is relevant for both 
small and large companies.

The operation of the investigated product was originally planned with an environment containing chlorides. Therefore, AISI 304L steel was chosen as the material. This steel is commonly used in products where it is necessary to provide corrosion resistance. [12]. Differences from AISI 304 steel are in a lower carbon content to reduce the possibility of intergranular corrosion [13]. The Russian analogue of steel 304 is steel $08 X 18$ N10 [14]. A visual inspection of the equipment revealed corrosion damage and corrosion products on the outer wall of the vessel (Fig. 1). To identify the causes of destruction from the product, segments with and without welded joints were selected. Many corrosion products near the welded seams suggested that the main cause of the destruction could be poor-quality welding work. To establish all the factors that led to the destruction, methods of visual-measuring control, metallographic studies, capillary flaw detection, and intergranular corrosion tests were used.

The aim of the work is determination the cause of capacitive equipment destruction during operation.
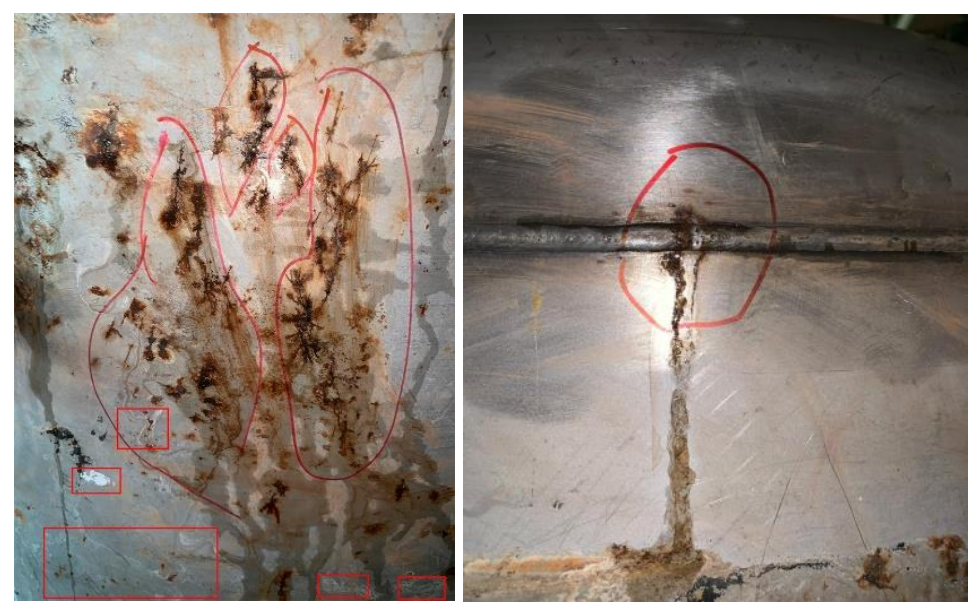

Figure 1: Corrosion Defects on the Outer Surface of the Container.

\section{EXPERIMENTAL METHODS}

The work investigated segments taken from damaged equipment, both with welded joints and without. To analyze the chemical composition of the steel under study, the method of atomic emission spectroscopy was used using an Iskroline100 emission spectrometer in accordance with GOST 54153-2010.

For metallographic studies, samples cut from destroyed parts were pressed in, and their surface was subjected to grinding using abrasive paper of 120-1200 grid grain size and polishing using polishing cloths on a BUEHLER ECOMET 4 grinding and polishing machine. The structure was investigated by optical metallography using a Reichert microscope Jung with $\times 200$ magnification.

To assess the tightness of welded joints, capillary flaw detection was carried out [15].

Intergranular corrosion tests were carried out according to the AMU method given in the GOST 6032-2017 standard [16].

\section{RESULTS}

Figure 2 shows the appearance of one of the investigated product segments. 


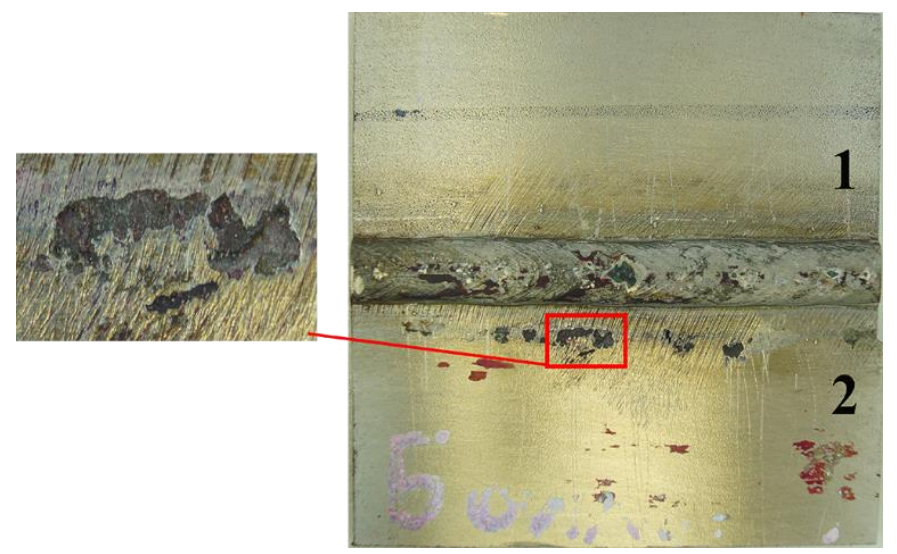

Figure 2: Sample of Investigated Product.

During visual inspection, the damage was localized in welded joints, as well as on the body under them. In the heat-affected zone, there were blind pits. All damage on the outer surface of the tank was found in the areas where the working solution was draining off. The cause of runoff is leakage of welded joints. As the working solution dries, corrosion products are formed on the outer walls of the product.

The results of chemical composition analysis are shown in Table 1.

Table 1: Chemical Composition of Tank Elements

\begin{tabular}{|c|c|c|c|c|c|c|c|c|c|c|}
\hline Sample o & Al & $\mathbf{C}$ & $\mathbf{C r}$ & $\mathbf{C u}$ & $\mathbf{M n}$ & $\mathbf{M o}$ & $\mathbf{N i}$ & $\mathbf{P}$ & $\mathbf{S}$ & Si \\
\hline 1 & 0,2 & 0,052 & 19,0 & 0,17 & 1,80 & 0,094 & 6,78 & 0,025 & 0,006 & 0,65 \\
\hline 2 & 0,032 & 0,080 & 18,3 & 0,15 & 0,96 & 0,132 & 7,7 & 0,038 & 0,0031 & 0,54 \\
\hline AISI 304 & - & $<0,08$ & $18,0-20,0$ & - & $<2,0$ & - & $8,0-10,5$ & $<0,045$ & $<0,03$ & $<1,0$ \\
\hline AISI 304L & - & $<0,03$ & $18,0-20,0$ & - & $<2,0$ & - & $8,0-12,0$ & $<0,045$ & $<0,03$ & $<0,75$ \\
\hline
\end{tabular}

Analyzing the data obtained, it can be noted that the material used in the manufacture of capacitive equipment does not correspond to AISI 304L steel. The carbon content is exceeded, and the nickel content is reduced. Sample No. 2, in contrast to sample No. 1, has magnetic properties. Figure 3 shows samples with a welded seam taken from the product before and after testing.
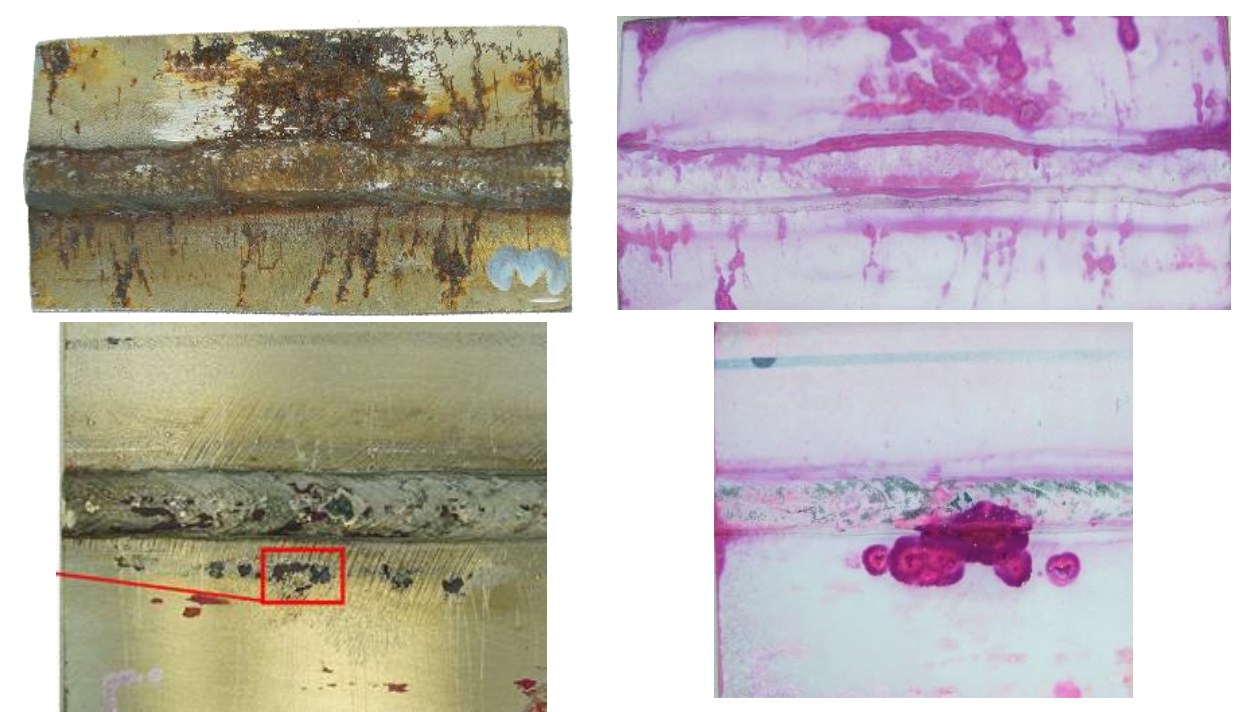

Figure 3: Samples After Capillary Flaw Detection. 
Based on the results of capillary flaw detection, both cracks in the heat-affected zone and defects in the welded joint were found. On the inner surface of the welded seams, there are zones with insufficient root penetration and the exit of the weld metal beyond the boundaries of the welded joint (Figure 4).
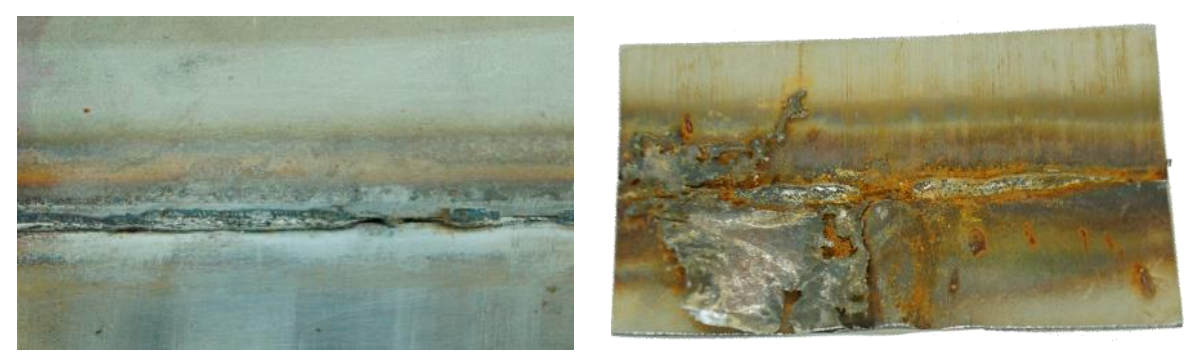

Figure 4: Defects of the Weld on the Inner Surface of the Container.

The results obtained as a result of visual inspection and capillary flaw detection allow to speak of non-compliance with the requirements of regulatory documents during welding, as well as the absence of acceptance control of welded joints.

The purpose of metallographic studies was to assess the nature of the destruction. Samples were taken from a weld, a cracked plate, and a cracked plate. A defect in the bead was found on the weld specimen (Fig. 5).

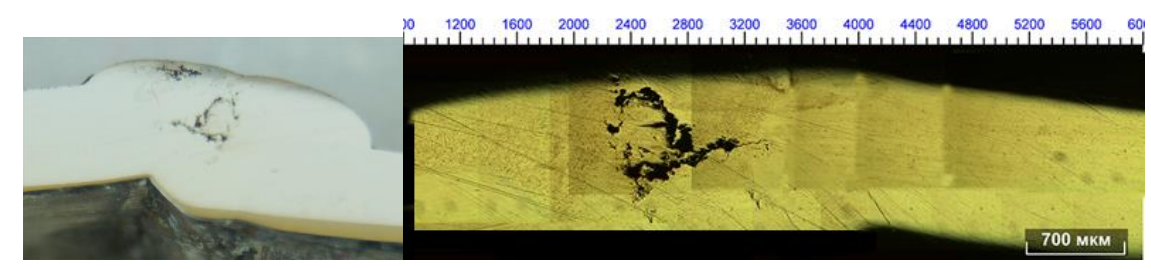

Figure 5: Defect in the Weld Metal, $\times 25$.

In a specimen with a branched network of cracks, a wide opening of the crack edges was noted, which indicates the presence of a stressed state (Fig. 6). A metallographic section was prepared in cross section.

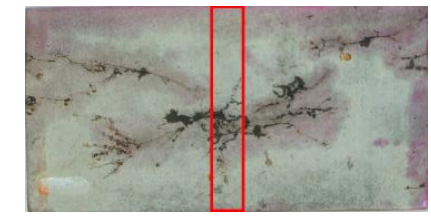

a

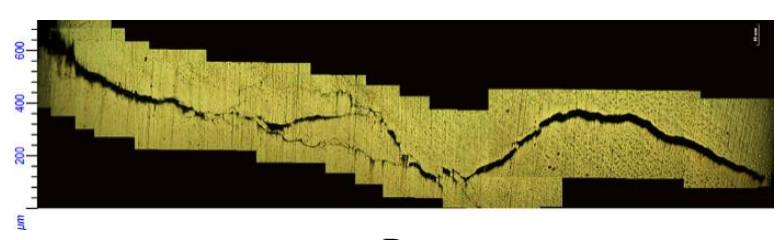

B

Figure 6: Crack in the Wall of the Water Heating Tank, $\times 25$ : a - Place of Cutting; $b$ - Crack in Metal Thickness.

Cracked defects on the wall of the water heater are most likely due to stress corrosion cracking. The reason for the occurrence of such a defect is the presence of a stressed state of the metal and an aggressive environment. The stress state arises during the production of a product (bending, welding), and chlorides (salts) can act as initiators of corrosion processes.

Metallographic analysis of the structure of metals with different magnetic properties showed differences in the microstructure (Fig. 7). The steels belong to the same class, but probably to different heats or supplies. 


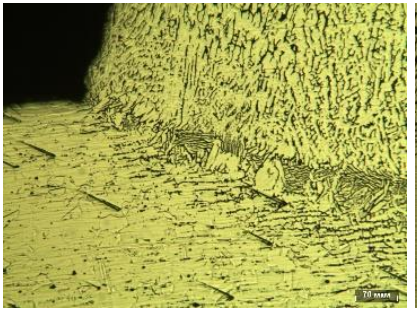

(a)

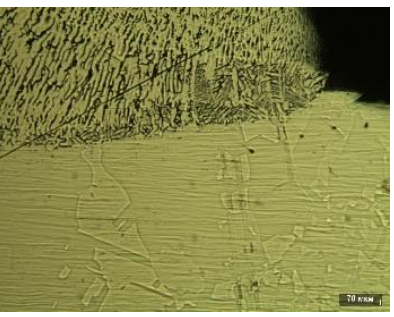

(b)

Figure 7: The Microstructure of the Welding Area, ×200: a Magnetic Section, b - Non-Magnetic.

Steels of this type can be prone to intergranular corrosion, especially in the presence of welded joints, therefore standard tests were carried out to assess the material resistance. Tests for intergranular corrosion have shown the tendency of the samples to this type of destruction. Figure 8 shows the microstructure of the tested sample.
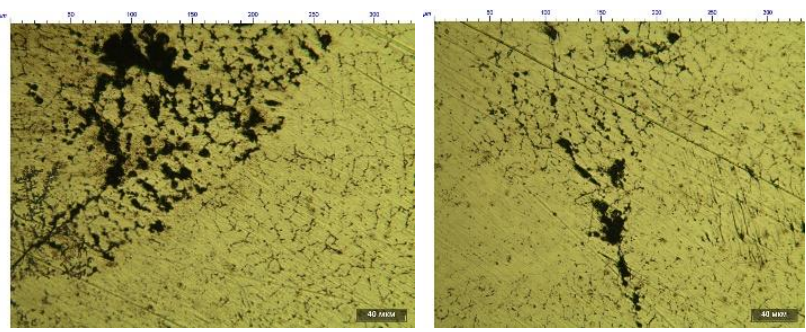

Figure 8: Microstructure of a Sample After Testing for Intergranular Corrosion, ×200.

Etching along the grain boundaries indicates the tendency of the material to intergranular corrosion. No cracks were found on the specimen without welded joint and HAZ after intergranular corrosion tests.

Therefore, sensitization of the steel and the formation of chromium carbides and chromium-depleted regions near the grain boundaries can be confirmed.

\section{DISCUSSION}

Cracks are the main defect found in the studied samples. In most cases, they are in the heat-affected zone, but there are also networks of cracks on the surface of the product without welded joints. At the same time, no corrosion damage was found on the inner surfaces of the water heating tank. Weld cracks can be caused by irregularities in welding technology. The most likely scenario for the occurrence of corrosion damage on the outer wall of the tank is as follows: 1. Defects in welded joints (cracks, incomplete penetration of the weld root) 2. Leakage of working solution through defects in the welded joint 3. Local increase in corrosive elements $(\mathrm{Cl})$ on the outer surface 3 . The increased concentration of corrosive elements on the outer wall together with the stressed state led to the formation of intergranular cracks both in the heataffected zone and in the zone without welds.

The investigated case includes most of the technological violations possible for similar products, which subsequently led to equipment failure. Probably, errors were made at the stage of checking the received metal products, since the investigated elements of the product differ in their chemical composition and magnetic properties. To prevent such incidents, it is necessary to develop and comply with the requirements of design documentation and at the same time implement effective methods of control of finished products. In the considered case, it was necessary to provide $100 \%$ input control of the chemical composition of the metal products used, to develop a unified welding technology and to carry out acceptance control of welded joints, as well as to carry out acceptance tests for intergranular corrosion. 


\section{CONCLUSIONS}

The steel used for the manufacture of the product does not meet the requirements for chemical composition. This is confirmed by both chemical analysis and the difference in magnetic properties.

There are defects in welded joints - incomplete penetration. This led to the ingress of the working solution on the outer surface of the product.

Intergranular corrosion tests have shown the tendency of the material used to this type of destruction. Destruction of this type caused equipment failure.

To avoid the repetition of such damage, it is necessary to adhere to manufacturing technologies and control at all stages of production.

\section{REFERENCES}

1. McEvily, Arthur J., and Jirapong Kasivitamnuay. Metal failures: mechanisms, analysis, prevention. John Wiley \& Sons, 2013.

2. Study of corrosion behavior of carbon andlow-alloy steels in CO2-containingenvironments, Kostitsyna, I., Shakhmatov,A., Davydov, A., E3S Web Conf., 121 (2019)

3. Corrosion testing of experimental steels foroilfield pipelines, Alkhimenko A., E3S Web of Conferences 121, 01001 (2019)

4. Laptev, A., Bugay, D. Fighting against corrosion in oil and gas complex of Russia: Problems and the ways of their solving. 2010. European Corrosion Congress 2010 - EUROCORR 2010.

5. Akhiyarov, R.G., Laptev, A.B., Movenko, D.A., Belova, N.A. The study of the ultralow corrosion resistance of tube steel for heat exchange equipment in oil refining. 2016. Neftyanoe Khozyaystvo - Oil Industry. (1), c. 118-121

6. Jones, David Rayner Hunkin. Failure analysis case studies II. Elsevier, 2013.

7. Makhlouf, Abdel Salam Hamdy, and Mahmood Aliofkhazraei, eds. Handbook of Materials Failure Analysis with Case Studies from the Oil and Gas Industry. Butterworth-Heinemann, 2015.

8. Papavinasam, Sankara. Corrosion control in the oil and gas industry. Elsevier, 2013.

9. Comparative analisys of corrosion resistance of S31200 duplex stainless steel and its analogue, Andrey Lapechenkov, Aleksandr Fedorov, Ekaterina Alekseeva, Lyudmila Galata and Aleksey Piskarev, Materials today: proceedings · February 2020 .

10. Affonso, Luiz Octavio Amaral. Machinery failure analysis handbook: sustain your operations and maximize uptime. Elsevier, 2013.

11. Effect of Production Factors on Main Oil Pipeline Pipe Metal Property Formation, Ermakov, B.S., Shaposhnikov, N.O., Metallurgist 62(7-8), DOI: 10.1007/s11015-018-0718-7

12. Llewellyn, David, and Roger Hudd. Steels: metallurgy and applications. Elsevier, 1998.

13. Kumar, B. Ravi, et al. "Effect of texture on corrosion behavior of AISI 304L stainless steel." Materials Characterization 54.2 (2005): 141-147.

14. Zubchenko, Alexander Stepanovich. "Brand of steels and alloys." (2011).

15. ISO 3452-1:2013 Non-destructive testing - Penetrant testing - Part 1: General principles 